\title{
2. Driving Change to Bring About Better Implementation and Delivery
}

\section{Peter Shergold, Secretary, Department of the Prime Minister and Cabinet}

There are three particular reasons I am glad to have the opportunity to 'set the scene' for this monograph. First, it is been two years since the last time I spoke out on issues of implementation and delivery, ${ }^{1}$ and over two years since I established the Cabinet Implementation Unit. The conference, and this monograph, provide a good opportunity to maintain the impetus towards the better execution of government policy. My experience of bureaucratic inertia is that if one does not keep driving forward one does not stop still: one actually slides backwards down the mountain of good intentions.

Second, two years of experience of the Cabinet Implementation Unit has produced valuable lessons about the barriers to successful implementation and how they might be planned for and overcome. These issues are being explored across all the Australian jurisdictions, as well as in the UK and New Zealand. This conference provides us with an opportunity to learn from each other.

Third, I want to continue a campaign to take the issues of project and program management out of the technical context into which they are all too frequently consigned. I have a simple message: project management is too important to leave for nerds!

When I was at school, participation in the Cadet Force was voluntary. Nevertheless attendance was remarkably high - not least because the alternative activity for Tuesday afternoons was a double lesson of Latin. For me, and many others, marching around the quadrangle or crawling through muddy fields seemed far preferable to conjugating the inflected forms of Latin verbs. And, to be truthful, if the alternative had been instead a long afternoon of something called 'project management' I might still have preferred to have spent my Monday nights polishing my boots, creasing my trousers and daubing my puttees. Project management can sound dull if worthy, a matter of routine process, necessary but uninspiring.

It is not. It is about getting things done through innovative methods, organisational change and committed leadership. And its significance to public administration is even greater. The quality of the implementation of government policy is central to community support for the institutions of democratic governance, a theme to which I will return. 
Although issues of implementation and delivery are attaining a higher profile in the Australian Government sector, the Cabinet Implementation Unit still gets told too often that 'the only reason we're preparing this implementation plan is because you're making us do one'. This is simply not good enough. If we are fair dinkum about accountability to our respective governments, and through them to the public, we must embed implementation planning into our routine. If planning to deliver is perceived as an additional chore, just more bureaucratic red-tape, then we will have failed.

Better project and program management cannot be left as a technical task for specialists. It is about ensuring that our organisations are able to change in order to deliver change effectively. Australian public servants face implementation challenges somewhat different from their private sector colleagues. They are marked by agency demarcations, overlapping jurisdictional responsibilities, and public accountability within an environment of fierce political contest and intense scrutiny.

And the implications of inadequate management of public policy can be worse. Poor delivery - such as inadequate service levels, lack of timeliness or burdensome regulatory processes - risks public dissatisfaction. It can reduce trust not only in public service but in the government it serves. Poor project management means that citizens are not receiving their entitlements and, in my view, that's even worse than customer dissatisfaction or a decline in shareholder value.

Implementation is necessarily a learning process. The changing circumstances and the experience of executing a policy decision have to be taken into account. Indeed they may require the policy decision to be revisited. Getting things done well in government requires more than a series of commandments (regulations, rules and guidelines) handed down to those below or transmitted from the national office to regional offices. Communication and learning have to work both ways. Policy prepared without the experience of those who deliver it across counters or from call-centres is almost certainly policy that will be poorly designed and difficult to implement.

Let me set out some of what we have learned in the two years since we established the Cabinet Implementation Unit. The Unit, as you are probably aware, lies at the centre of government. It taps into the Cabinet decision-making process, through which almost all the big decisions of the Australian government are made. It does three things:

- As policy submissions are being prepared for Cabinet consideration, the Unit works with drafters to ensure that the proposals that Ministers consider provide a summary of implementation issues, including an assessment of 
expected benefits, governance, milestones and risks: the goal, quite simply, is to ensure that government can decide on policy with its eyes wide open.

- For important initiatives that pose significant implication challenges, the Unit then works with agencies to develop more detailed implementation plans against which progress can be regularly reported to the Prime Minister and the Cabinet.

- On a quarterly basis, the Unit compiles short reports from agencies, in a tabular, 'traffic light' format to ensure that the government has a snapshot of how implementation is going on large or sensitive projects. The latest report covers around 150 specific initiatives of which 26 have been given 'amber' or 'red' light status.

The first thing I've learned over two years is that the successful implementation of policy is not about the adoption of any particular project management methodology, although it is essential that an appropriate methodology be employed. Increasingly it has become apparent that the pathway to better implementation is that it be consciously driven from the top down with continuing executive oversight. Chief Executive Instructions create a framework for due process and accountability but they do not convey the commitment and interest of leadership in implementation.

There is nothing particularly original about this insight. A recent report on IT projects around the world found that less than one third succeeded: 53 per cent did not meet expectations in terms of their timing, cost or capacity to deliver the required features and functions and 18 per cent failed completely. One of the most critical factors determining success was executive management support, in championing and resourcing projects ${ }^{2}$ and, equally important, in making sure that there were systems in place ensuring that the right projects were selected at the right time for the organisation.

This does not mean that the heads of agencies need to go off and study the Project Management Book of Knowledge, or PRINCE2. But it does mean that they have to learn the right kind of questions to ask. In her November 2004 address to the Australian Graduate School of Management/Harvard Club of Australia, Christina Gillies ${ }^{3}$ emphasised:

In most boardrooms, good financial governance is understood and operates without question. Even where directors have little or no experience in financial analysis, they are aware that they must obtain a level of understanding of the financial operations of the business and have sufficient basic knowledge to interpret the books of account ... (But) for many directors, IT is a subject to be avoided. How can a director with little or no experience in IT carry out their fiduciary duties, when struggling to understand the terminology and ever-changing nature of technology? 
Senior public sector managers, who find themselves charged with the oversight of major programs and projects must know what the right questions are, who might be able to answer them and how to assess the validity of the answers. With this in mind, the Cabinet Implementation Unit and the Australian National Audit Office have been working jointly on a better practice guide to implementation. The guide is not primarily about how to manage projects and programs. Rather it provides a checklist of the types of questions that need to be asked and the assurance that needs to be given to CEOs, the senior officers responsible for oversight of projects and the project managers themselves. Such a systematic approach is the key to driving the structural and behavioural changes needed in organisations if good intentions are to be turned into better practices.

The Palmer inquiry ${ }^{4}$ into the Department of Immigration, Multicultural and Indigenous Affairs' management of detentions and deportations reveals much of what can go wrong when government policy is not effectively translated into organisational systems and processes. Palmer found that DIMIA, and by extension all public sector agencies, should have in operation 'systems that ensure integrity of application and accountability and engender public confidence ... and searching processes of high-level internal review (to ensure) the organisation is achieving the outcomes expected of it. Such corporate quality assurance would (need to) be executive driven ...' (p165).

Most importantly Palmer also highlighted the danger of workplace cultures preoccupied with process and rule-driven operational practice. The risk of depending upon systems alone is that implementation degenerates either into blind application of processes or into instructions which, not effectively monitored, are soon ignored. The tension between the need for systems and the need for learning can only be resolved by building into our organisations effective monitoring and communication and the will and capacity to make change in response. I think that this creative tension needs to be managed through robust, top-down project management practices mandated and championed by the agency leadership. People need to know that senior executives are serious.

I hope that the CIU may contribute to this goal. That is one reason why I have been keen to avoid the Unit becoming a centralised cudgel-wielding bureaucratic elite - what Charles F. Sable has recently called 'a commando centre' 5 or what Evert Lindquist, who is also speaking at this conference, calls 'a temporary adhocracy'. I see the Unit as a vehicle for communicating more effectively between those implementing government policy, public service leadership and government. In that role it has obvious opportunities for contributing to learning, including - formally and informally - by advising, coaching and mentoring on the basis of its accumulating experience. But to do so it has to be driven by a 
spirit of collegiality and cooperative partnership, not of imposed authority and blind obedience. It is about learning by doing and then spreading the learning. Senior management has to play an increasingly important role in linking individual projects to wider organisational strategies and goals, and shaping those goals on the basis of what has been learned from individual projects. ${ }^{6}$ They need to understand that policy development and service delivery are not in a linear chronological relationship. The making and executing of government policy is an iterative process. We can only avoid policy blunders by ensuring that policy-making is routinely and constructively informed by service delivery, in a way that transcends traditional boundaries and structures.

Learning is also prominent in the logic of the system of Gateway Reviews, developed by the UK's Office of Government Commerce, adopted by the Victorian Government and now to be introduced at the Commonwealth level. Gateway is a response to concerns about the risks of major projects going on for too long without delivering. You will shortly be hearing from other speakers on the detail of Gateway, including from Ian Glenday, who will share his experience of the OGC with us.

A central feature of Gateway which particularly attracted me was that the reports from peer review teams will be confidential to the project's senior responsible owner. This is not only to facilitate full and willing access to project data by the review teams. Crucially, it is also to facilitate learning between peers and a focus on overcoming challenges rather than denying problems, designing alibis or allocating blame.

In thinking about Gateway, for example, one might want to explore what the introduction of these independent peer reviews will mean for agencies. Are we ready for Gateway? Have we, for example, adopted consistent project management practices and methodologies across our agencies so that, if a Gateway team were to ask for the relevant documentation, or to speak to the relevant stakeholders, such information would be immediately to hand? Do we have sufficiently robust project governance practices in place to respond to the warnings and advice such reviews are designed to provide? What avenues have been established within and across our agencies to capture lessons from individual projects and disseminate them more widely?

In posing these questions I do not want to suggest that public servants are ill-prepared. My sense is that departments have responded well to the increased emphasis on project management. I now see a lot more preparatory thought on the best options for delivery, what sort of risks may emerge and how they will be handled. I discern a better articulation of the program logic and a greater understanding that effective implementation will improve the quality of the policy itself. 
But we need to go further. As the outcomes of the most recent meeting of the Council of Australian Governments (COAG) powerfully demonstrated policies of national significance increasingly have to be delivered across jurisdictional boundaries. The new National Reform Agenda spans increased economic competition, greater investment in human capital and a less intrusive regulatory regime. When individual elements of this bold agenda are brought before governments for decision - as they must be if they are to be designed and costed - it will be crucial for governments and public servants to understand how all these pieces fit together. How does this project impact or depend on others? How can we identify appropriate pathways to deliver expensive, long-term projects, when we anticipate that the technological environment is likely to change substantially during the course of their implementation? How can we identify where the boundaries of relative certainty lie, and how we will gradually expand them in response to evolving circumstances? Can Commonwealth, State and Territory public administrations, with their inevitable bureaucratic demarcations, together develop a clear picture of the decisions that will need to be taken, when, and by whom, and the associated critical paths, risks, and interdependencies?

These are the sorts of challenges that already emerge as agencies lodge implementation plans with the CIU. Departments frequently find that they do not have the answers to all of the questions when they work up the first cut of the plan. That's quite normal. There are nearly always a swag of unknowns particularly when implementation depends legislative enactment, jurisdictional cooperation, joint funding or outsourced delivery through contracted third-parties. This is precisely where the disciplines of project and program management provide a sound basis for decision making in an environment of uncertainty. By forcing questions around the scope of a measure we clarify expectations and align deliverables with expectations; by forcing questions around timing, we clarify the critical points at which decisions about the next stage of a project will need to be made; by forcing questions around costs and benefits, we can disaggregate investment down into phases that help to understand what is known, and what might have to wait for legal, technological or political issues to be resolved.

Project management in the public sector is not just a matter of ensuring that government decisions are delivered to citizens efficiently, ethically and courteously while paying close attention to the appropriate and effective use of public funds. It is about more than service, timeliness and value for money. It is also about recognising that the implementation of government policy can often intrude on the lives of citizens, and impose costs on businesses, in ways that undermine self-responsibility and stifle entrepreneurship. 
Bureaucratic red tape can impose regulatory costs, the scale and dimensions of which are often not sufficiently appreciated by governments who legislate and public servants who administer. There is a rising sentiment in the Commonwealth, State and Territory governments (and overseas) that it is better to regulate less and to regulate better. It is for that reason that the Banks Taskforce into Reducing Regulatory Burdens on Business was established. It will shortly deliver its findings to the public.

I am certain the report will require us to ask hard questions about the effect of regulatory policy on Australia's society and economy. Good program and project management should involve consideration of the scope of regulation and how its costs - including costs arising from uncertainty - can be reduced. Has scope creep meant businesses not originally intended to be subject to the regulation are being captured? To what extent are overlapping and inconsistent regulatory requirements across federal boundaries imposing additional burdens? Are regulations or reporting requirements justified by the original policy intent, or have they become redundant or does the policy outcome no longer justify the compliance cost. Are reporting requirements resulting in same or similar information being provided to multiple agencies? Do variations in definitional and operational reporting cause confusion in their application?

Reducing the regulatory burden on business will be a complex exercise. It will involve systemic reforms to improve regulation-making and enforcement. It will require project managers to assess the external costs of implementation on those who are subject to compliance regimes. But change - significant change - is already afoot. The Department of Industry, Tourism and Resources has developed a costing tool to better equip public servants to identify and, where possible, quantify the regulatory impact of new policy measures on businesses. It will become a requirement for this costing tool to be used in all Cabinet Submissions that propose regulation on business, to enable Ministers to make more informed policy decisions. In addition to this, the Productivity Commission will be asked, on an annual basis, to examine areas of regulatory concern to business to identify areas that could be improved. 
Many of you would be aware that John Uhrig was appointed in November 2002 to conduct a review of the corporate governance of Commonwealth statutory authorities and office holders. The objective of the review was to look at the governance arrangements for statutory authorities and office holders, and come up with options for improving their performance and getting the best from their accountability frameworks. Uhrig was asked to develop a broad template of governance principles and arrangements for statutory authorities and office holders, and potentially beyond, to a wider range of public sector bodies.

Many of you would be aware that, in response to the Uhrig review more than 160 Australian Government agencies are currently being assessed against agreed governance principles. This progressive process is leading to changes in governance structures. It also involves a system of issuing Statements of Expectation to, and receiving Statements of Intent from, various authorities. Such statements will help to communicate and inform government expectations.

At the same time the Government has brought six key human services delivery agencies into the new Department of Human Services. The Department provides direct accountability to a single Minister who is responsible, in Cabinet, for ensuring that the costs and timing of administrative change are factored into consideration of health, child support or welfare policies. I can see that this discipline is already influencing for the better the policy decisions that are being taken.

- Peter Shergold

The increased interest by governments in reducing regulatory impositions illustrate the manner in which the environment of public policy changes. It will influence the character of, but not the need for project management of public policy. And there are at least three ways in which the requirements for effective execution of policy are likely to remain constant:

- first, that the disciplines of project and program management are not an end in themselves. They are the means by which the public service can best balance the increasing demand for change and adaptation by governments and the electorate with the need for administrative, technical and financial efficiency, service quality and structural innovation in program delivery;

- second, project and program management are a way of communicating from the bottom up and from the top down within and across organisations. For this to be an effective process, the senior executive must be as engaged in the development of agency capabilities in this area as the project managers themselves; and 
- third, they will need support in this role. This support will not primarily be in the form of workshop training in project management techniques, but will require innovative ways of supporting senior executives in fulfilling their responsibilities, including through coaching and mentoring.

As I noted at the beginning, 'project management' would not have been a school subject that attracted me. Perhaps though if it had been called 'action' with an emphasis on 'getting things done fast and well' it might have caught my attention. Certainly that's why I am such an enthusiast now. To me project management is transformative - it turns the goals of public policy into acquisitions, investments, programs and services that are in the public interest. And that leads me, finally, to why I think project management is more than an important set of technical skills.

Public servants bear a particular responsibility, directly and indirectly, for the delivery of government policy. Every government knows that its future depends not only on how wisely it makes decisions but on how effectively its public service delivers them. In my interpretation of the Westminster tradition governments should continue or fall on how the electorate perceives the quality of their policies not on the competence of public officials to execute them. Indeed I think that public servants should exhibit bias ... but the bias they display should be for delivering public policy with vigour. I want project managers who are driven by a bias for action.

\section{ENDNOTES}

1 'Plan and Deliver: Avoiding Bureaucratic Hold-up', Speech to the Australian Graduate School of Management/Harvard Club of Australia, Wednesday, 17 November 2004, National Press Club, http://www.dpmc.gov.au/speeches/shergold/plan_and_deliver_2004-11-17.cfm

2 Sample research from the Standish Group, accessed at http://www.standishgroup.com/ sample_research/index.php

3 C. Gillies, 2005, IT Governance: A Practical Guide for Company Directors and Business Executives, CPA Australia

4 Accessed at http://www.minister.immi.gov.au/media_releases/media05/palmer-report.pdf

5 Sabel, C. F. 2004, 'Beyond Principal-Agent Governance: Experimentalist Organizations, Learning and Accountability', address to Netherlands Scientific Council for Government Policy (Wetenschappelijke Raad voor het Regeringsbeleid - WRR) 30 January. I thank Professor Ian Marsh for drawing this article to the attention of my Department.

6 Jugdev, K. and Muller, R., 2005, 'A Retrospective Look At Our Evolving Understanding of Project Success' in Project Management Journal, 36: 4. 